\title{
The Spiral of Silence Theory, The Sleeper Effect and The Third Person Effect on Public Opinion Take Zheng Shuang's Surrogacy Incident as an Example
}

\author{
Xinyi $\mathrm{Ji}^{1, \mathrm{a}, *, \dagger}$ Yuqing Song ${ }^{2, \mathrm{~b}, *, \dagger}$ Yuting $\mathrm{Wei}^{3, \mathrm{c}, *, \dagger}$ \\ ${ }^{1}$ School of Tourism and Hospitality Management, Yunnan University of Finance and Economics, Kunming, Yunnan, \\ China \\ ${ }^{2}$ School of Urban and Evironment, Yunnan University of Finance and Economics, Kunming, Yunnan, China \\ ${ }^{3}$ University of Delaware, DE, United States

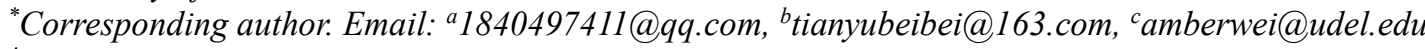 \\ These authors contributed equally.
}

\begin{abstract}
In January 2021, Zheng Shuang, a well-known Chinese actress, was widely discussed online because of her behaviour of surrogacy. This article focuses on analyzing the application of the spiral of silence theory, and the third person effect, and the sleeper effect in this event. And the event was divided into three stages: the beginning, the climax, and the end. We analyze the first stage with the spiral theory of silence combined with graphs, the second stage with the third-person effect, and the third stage with the sleeper effect. Through this case, we further analyze the impact of these theories on public opinion.
\end{abstract}

Keywords: the spiral of silence theory, the third-person effect, the sleeper effect, Zheng Shuang, surrogacy.

\section{INTRODUCTION}

With the advent of the information age, social media spread has accelerated and more widely. What's more, in the process of information dissemination, the public's views are easily guided by the media. Consequently, it is an essential topic that how social media influence public opinion.

The spiral of silence theory, the sleeper effect, and the third person effect are important theories of mass communication, social psychology, and public opinion. And recently, the incidence of the "Zheng Shuang surrogacy scandal" has been a hot discussion topic on major social media apps. We will combine the three theories to analyze the main direction of public opinion, why and how public opinion was influenced in this incidence.

\section{APPLICATION OF THE SPIRAL OF SILENCE THEORY IN ZHENG SHUANG'S SURROGACY INCIDENCE}

The Spiral Of Silence Theory is a theory of politics and mass communication, first proposed by a German scholar, Elizabeth Noel-Neumann, in a paper published in the Journal of Communication in 1974. The theory believes that individuals who deem that their views are consistent with the majority will boldly express and spread their views. Nevertheless, if they think they are a minority, they will remain silent or turn it to echo the mainstream views instead of spreading them. The silence of one side leads to the growth of the other side[1]. At the same time, mass media usually pays attention to the opinions of the majority and neglects the opinions of the minority[2]. This will form a trend of development that the voice of the dominant opinion is getting stronger, while the other side is becoming more and more silent.

On January 18, 2021, Zhang Heng, the former boyfriend of Zheng Shuang, who is a famous Chinese actress, posted on Weibo (a broadcast-style social media 
and network platform where Chinese Internet citizens share commonly short and real-time information, which resembles Facebook) that they have already two children. However, besides the topic of the well-known actress, Zheng Shuang, getting pregnant before marriage, netizens have focused more on "Whether Zheng Shuang had a surrogacy?"

Then, Zhang Heng exposed much cogent evidence on Weibo, including their parents' recording and children's birth certificates, proving that Zheng Shuang had a surrogacy. According to the recording, Zheng Shuang's family intended to abandon the two kids and said a series of words without humanity, such as " These two kids have been seven months old and could not be aborted, fuck!" and " As long as the children are born, we give them away."

On January 18, Zheng Shuang was in the public opinion center of surrogacy because of a series of convincing pieces of evidence posted by Zhang Heng. During this period, Zheng Shuang's family responded and explained many times. What's more, on January 23, her father officially apologized for the surrogacy and abandonment, but netizens did not buy it.

This article summarizes the hot topics regarding this incident on social media platforms, especially Weibo, as shown in the figure below.

Table 1. Summary of the hot topics on Zheng Shuang event on Weibo ( as of 2021.1.19)

\begin{tabular}{lllll}
\hline & Date & Hot titles & $\begin{array}{l}\text { The number of times } \\
\text { people read online(a } \\
\text { hundred million })\end{array}$ & $\begin{array}{l}\text { The number of times } \\
\text { people } \\
\text { online(ten thousand) }\end{array}$ \\
\hline 1 & 2021.1 .18 & Zhang Heng, babies & 3.2 & 5.6 \\
2 & 2021.1 .18 & Zhang Heng, of course, they are my babies & 21.9 & 14 \\
3 & 2021.1 .18 & Zhang Heng posted an article & 35.1 & 52.8 \\
4 & 2021.1 .18 & a recording of Zheng Shuang and Zhang Heng's parents & 30.1 & 57.7 \\
5 & 2021.1 .18 & $\begin{array}{l}\text { the birth certificate of Zheng Shuang and Zhang Heng's } \\
\text { children }\end{array}$ & 32.4 & 59.7 \\
6 & 2021.1 .19 & Zheng Shuang and Zhang Heng opened the second trial & 9.5 & 9.5 \\
7 & 2021.1 .19 & Zheng Shuang refused to mediate & 4.1 & 7.3 \\
8 & 2021.1 .19 & Zheng Shuang's response & 14.1 & 36.5 \\
\hline
\end{tabular}

In the spiral theory of silence, the more detailed and credible the information described, the higher the public's attention to the event. From table one, it can be found that after Zhang Heng admitted "of course my baby" on January 18,2021 , the increase in the credibility of this incident led to that an increasing number of the public read the details online. Also, when Zhang Heng posted an article as a detailed response to this incident, there was a steep increase in the number of public discussions, rising from 140 thousand to 528 thousand. In the face of the highly credible response, the public was no longer silent, and they started to discuss on Weibo. The previous high reading converted into a high discussion. According to the data in the table, it can be seen that when it came to "Zhang Heng posted an article" and "a recording of Zheng Shuang and Zhang Heng's parents" as well as "the

Table 2. Initial media's opinion statistics (Data comes from Shanxi Province Key Public Opinion Information Research Center)

\begin{tabular}{|c|c|c|c|}
\hline Source platform & Media type & Time & Title \\
\hline Sina Weibo & $\begin{array}{l}\text { Official media } \\
\text { [CCTV News] }\end{array}$ & $\begin{array}{l}2021.1 .19 \\
15: 00\end{array}$ & $\begin{array}{l}\text { A star was suspected of being a surrogacy. In the recording, "The } \\
\text { child could not get beaten off, I am extremely annoyed" was angrier. } \\
\text { Surrogacy is forbidden in our country, and her disregard for life is } \\
\text { abhorrent. }\end{array}$ \\
\hline Qutoutiao & $\begin{array}{l}\text { Entertainment } \\
\text { media }\end{array}$ & $\begin{array}{l}2021.1 .19 \\
15: 00\end{array}$ & $\begin{array}{l}\text { Zheng Shuang responded to it firstly, saying she had not violated the } \\
\text { law and been blackmailed, but avoided talking about her children. }\end{array}$ \\
\hline $\begin{array}{l}\text { Tencent } \\
\text { Reading }\end{array}$ & $\begin{array}{l}\text { Entertainment } \\
\text { media }\end{array}$ & $\begin{array}{l}2021.1 .19 \\
15: 00\end{array}$ & $\begin{array}{l}\text { Reporters visit surrogacy agencies secretly. This video, please let } \\
\text { more people see! }\end{array}$ \\
\hline WeChat & WeChat & $\begin{array}{l}2021.1 .19 \\
15: 00\end{array}$ & $\begin{array}{l}\text { Zheng Shuang responded to "surrogacy and abandonment ", CCTV } \\
\text { News criticized her severely! She's not stupid. She's bad! }\end{array}$ \\
\hline Zhihu & 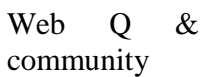 & $\begin{array}{l}2021.1 .19 \\
15: 00\end{array}$ & $\begin{array}{l}\text { Zheng Shuang responded to the surrogacy and abandonment } \\
\text { incident, saying that "I have repeatedly refused to expose privacy and }\end{array}$ \\
\hline
\end{tabular}




\begin{tabular}{|c|c|c|c|}
\hline & & & $\begin{array}{l}\text { extorted, also did not violate national instructions and foreign laws ", } \\
\text { what do you think? }\end{array}$ \\
\hline Sohu Video & Sohu Video & $\begin{array}{l}2021.1 .19 \\
15: 03\end{array}$ & $\begin{array}{l}\text { CCTV News commented on surrogacy: it is against the law and } \\
\text { morality. }\end{array}$ \\
\hline Sina Blog & Social media & $\begin{array}{l}2021.1 .19 \\
15: 44\end{array}$ & $\begin{array}{l}\text { CCTV criticized Zheng Shuang's conduct of surrogacy and } \\
\text { abandonment angrily. }\end{array}$ \\
\hline Weibo & Official media & $\begin{array}{l}2021.1 .19 \\
19: 59\end{array}$ & $\begin{array}{l}\text { Zheng Shuang surrogacy took advantage of the legal loophole, which } \\
\text { is by no means innocent! }\end{array}$ \\
\hline $\begin{array}{l}\text { Sichuan Legal } \\
\text { News - the } 003 \\
\text { rd Edition: Rule } \\
\text { of Law China }\end{array}$ & Press & $\begin{array}{l}2021.1 .20 \\
00: 02\end{array}$ & $\begin{array}{l}\text { An actress is suspected of being a surrogate, also trapped in a lending } \\
\text { dispute. }\end{array}$ \\
\hline
\end{tabular}

In a period from 15:00 on January 19 to $00: 02$ on January 20, all of these eight media outlets focused on the topic of surrogacy in this incident. Within an hour after the CCTV News, Sohu Video and Sina Blog have commented on CCTV's comment on Zheng Shuang surrogacy. Under the influence of the official media, the intersection of their views was soaring. At the same time, after CCTV News posted an article about surrogacy on Weibo, public views on the Weibo platform also focused on various topics relating to surrogacy.

Also, after browsing through the public views on Weibo, we found that over $70 \%$ of topics concentrated on the severity of surrogacy, not just expressed views on Zheng Shuang's behavior. However, in the two hours, before these media posted articles, the number of people whose comments were related to surrogacy was 162,616 in total, only consisting of $8.8 \%$.

From what has been analyzed above, we can conclude that the voice of these media had led the public's comments from the personal conduct of the actress to a larger social topic - surrogacy.

In the different types of media platforms, the spiral of silence is also different for the direction of public guidance. On the influence of the article posted on the forum - type media - "Zheng Shuang responded to the surrogacy and abandonment incident, saying that 'I have repeatedly refused to expose privacy and extorted, also did not violate national instructions and foreign laws', what do you think?" , the Internet citizens were provided a platform where they can share their opinions randomly on the incident. Under this topic, some of the most popular comments were about "Zheng Shuang's parents' utilitarian education "," the surrogate business behind Zheng Shuang" and more comments surrounding "Zheng Shuang" instead of "surrogacy". The keywords of hot search are "eating melon"," Zheng Shuang "," female star surrogacy "," Zheng Shuang's mental state" and so on.

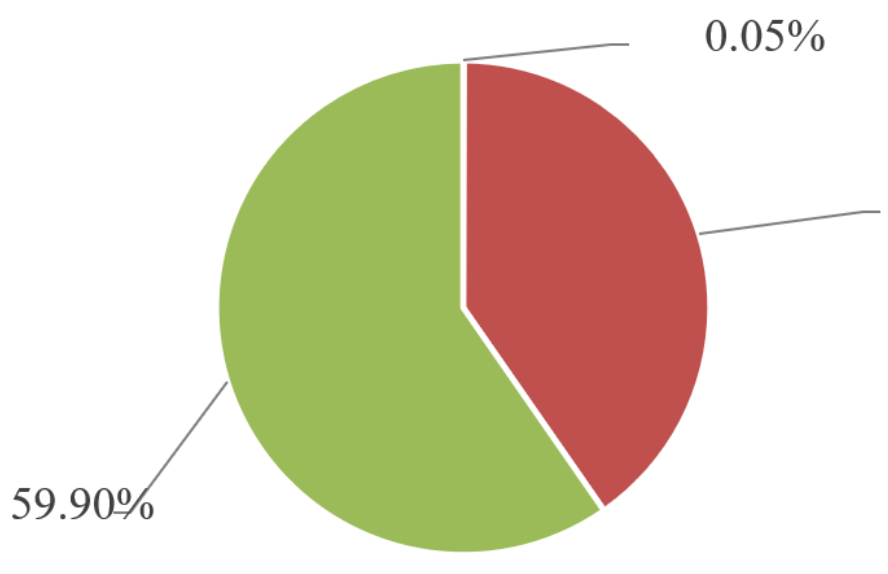

$40.45 \%$

- positive attitude

- Neutral attitude

- negative attitude

Figure 1 Public attitude towards Zheng Shuang incident (Data comes from Shanxi Provincial Key Public Opinion Information Research Center 


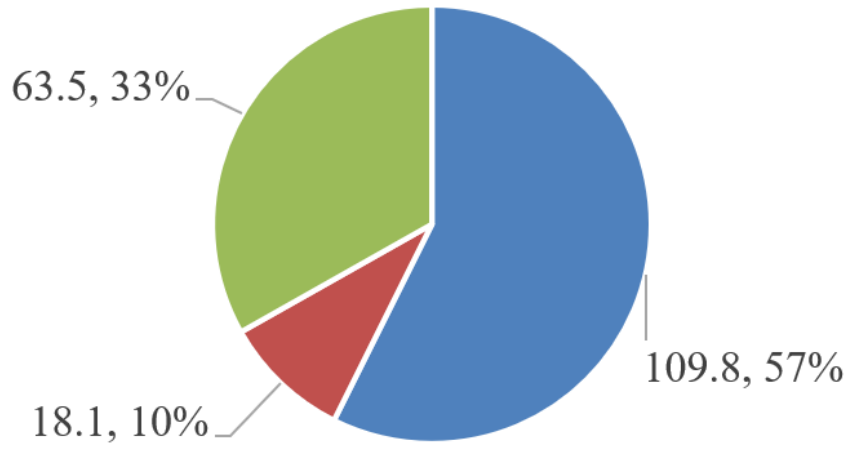

- Must quit the entertainment industry

- Should not quit the entertainment industry

- No matter whether she quits or not, no one dared to cooperate with her anymore

Figure 2 Public attitudes on whether Zheng Shuang should quit the entertainment industry (ten thousand) (Data from the Weibo Poll, as of 1.21)

As of January 21, under the influence of many media, netizens with negative attitudes dominated in Zheng Shuang incident. Among them, the number of people who held the negative and neutral attitudes is the mainstream opinions, the former making up 59.9\%, the latter making up $40.05 \%$, respectively. However, the proportion of people who held a positive attitude was only $0.05 \%$.

Combined with figure two, 1.098 million people supported her to quit the entertainment industry, accounting for $57 \%$, which was the most prevailing opinion. And 635000 people held the view that "No matter whether she quits or not, no one dared to cooperate with her anymore", which was equivalent to abstaining or neutral attitude, accounting for $33 \%$. The percentage of people who thought "should not quit the entertainment industry" lay the last, with $10 \%$. officially, some netizens are still neutral. In detail, Zheng Shuang's fans dominated among the neutral and positive groups. As of 23 January, Zheng Shuang's incident had begun to quell. However, in the Weibo discussion community, some fans still made a lot of positive comments, like "Belief Zheng Shuang " and " Everything will be better ". And among these related comments, the comment with the highest thumb up, with the number of 27000, which had 6595 relevant comments below in total.

Obviously, under the influence of the fan effect of stars, the minority opinion groups do not attach the mainstream views according to the traditional silent spiral phenomenon. Although it is a fact that the number of minority groups is declining, we can imagine that the speed of decline will become very slow when falling to a certain point. As shown in the figure below.

According to these figures, although many official media and entertainment media criticized Zheng Shuang

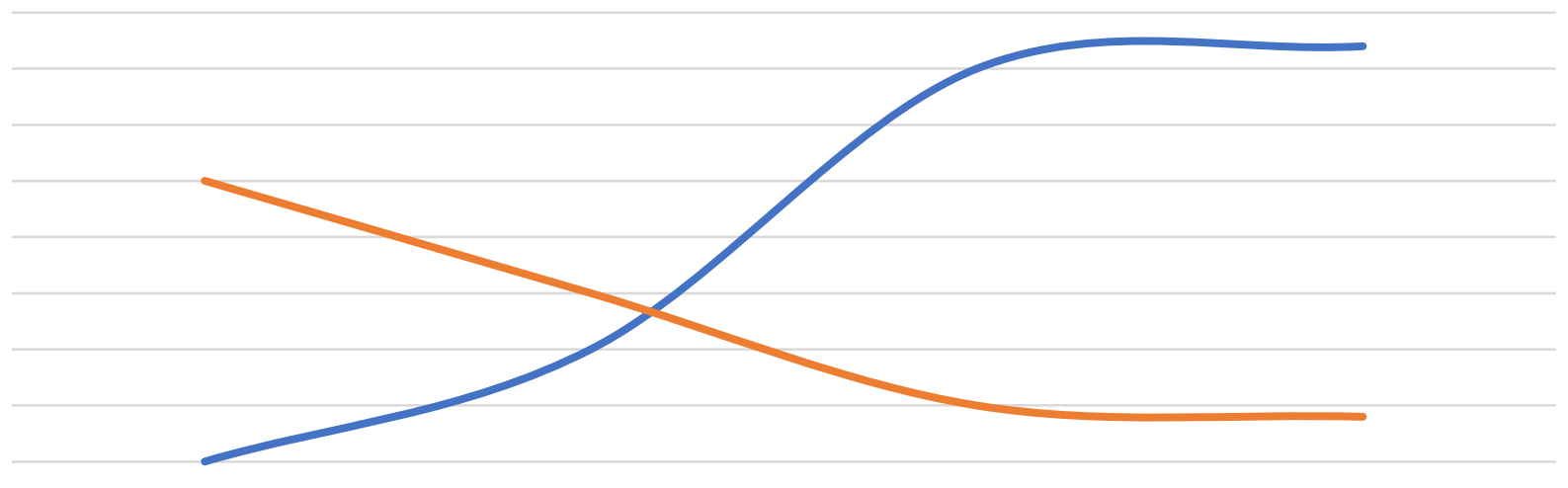

The number of people with negative attitudes

The number of people with positive and neutral attitudes

Figure 3 The influence of a star's fan effect on the spiral theory of silence. 


\section{APPLICATION OF THE THIRD PERSON EFFECT IN ZHENG SHUANG'S SURROGACY INCIDENCE}

The third-person effect, also known as the thirdperson effect, was first proposed by Professor Davidson of Columbia University in 1983 in a paper titled "The Role of the Third Person Effect in Communication". He believes that when people judge the influence of mass media, especially the negative influence, there is a general perception set. That is, they tend to think that the information of mass media may not have much influence on "me" or "you", but has an immeasurable influence on "other" people. Due to the effect of this perceptual set, the influence and effect of mass communication usually occur not directly in the surface audience targeted by the media but through the reaction behavior of the "third party" related to them. Generally speaking, things that have nothing to do with them will consider the problem from a bystander's point of view and attack it wantonly with an attitude that has nothing to do with them. However, people who are not personally experienced have a gap in the judgment of things[3].

Just as above, after sending the Weibo in Zhang Heng, a spiral of silence, let the outbreak of the theory of the third person is better, so far the national launch of the "entertaining" model, netizens report also followed, however, when two people before the case is not the key, get caught up in "surrogate" and "women don't want" if it is true friends care about most topics. Zhang Heng wants to be well aware of this point. After all, in the past year, there has been a lot of speculation, defamation, and abuse of Zhang Heng on the Internet, so Zhang Heng used the voice of netizens to fight back against Zheng Shuang.

After that, the media found Zhang Heng's friend to ask for details. Zhang Heng's friend provided the media with photos of Zhang Heng and his children in the United States. He says that Zhang Heng is indeed in the United States to take care of the two children and has not returned to China because Zheng Shuang does not cooperate with the legal procedures, resulting in the children not returning to China Zhang Heng also can not follow. That night, Zhang Heng releases a fierce material again through a friend, the telephone recording of two sides. In the recording, Zheng Shuang's father said that because Zheng Shuang and Zhang Heng broke up, they wanted to "do not" the reason for the surrogate child is "cannot afford to keep". So Zhang Heng's parents told the hospital to "abandon it".-- easier than applying for an online return. Zhang's father disagrees, reminding him: "It's against the law in America." In another recording, Zheng's family also offered to "adopt the child in the United States." The family didn't know what this meant, and Mr. Zheng interjected in a flurry of gibberish about how anxious he was. Zheng added: "I am responsible for what I have done in my own life." Abandoned children also called responsibly? After Zheng's parents tried to persuade Zhang's parents to find adoption in the US, Zheng suddenly chimed in: "I really can't beat the baby. I'm sick to death." Zheng Shuang's mother also said that the child consults lawyers to come out of the way. The child was born to send people. Let Zheng Shuang and Zhang Heng "completely forget". Zheng Shuang's mother also stressed that she should write down the conditions of the adoption and "never see each other again". She also speculated that the adopters did not want the children to know their birth history and hoped that the adopted children would think that the adoptive parents were their parents[3]. When Zheng Shuang said, "Fuck, I'm bored to death", Weibo was close to collapse countless times. Tens of millions of netizens followed it in real-time and started the hot discussion mode. A lot of criticism and abuse pushed the incident to the first climax.

The birth certificates of the two children were also found. The girl was born on January 4, 2020. The mother now uses the legal name Shuang Zheng and is 28 years old. His father's legal name is "Heng Zhang", his age is 29, and his father's birthday is February 16, 1990. At this point, Zheng Shuang and Zhang Heng married, gave birth to a child, divorced things have evidence. The Internet users have the same idea: "OMG, I know Zheng Shuang is crazy, did not expect so crazy......"'Only the majority of netizens cannot think of. No Zheng Shuang cannot do."

So why the netizens have such a strong reaction, and why are there so many attacks and abuse. In the third person theory, people usually consider problems from an outsider's perspective and comment on things that have nothing to do with them. First of all, Zheng Shuang, as a public figure, should have played a leading role. However, she not only failed to take the lead but also committed the illegal act of surrogacy. Followed by most Internet users is emotional, irrational, most of the time their view of events is purely based on their feelings. Stars as highincome people, itself is easy to cause some netizens resonance, such as hatred, especially before a surrogate issue, Zheng Shuang has just spent 150 million to buy new homes. And in the investigation process of the incident, Zhang Heng also reported that Zheng Shuang's single film salary is as high as 160 million. So the sum of money down is a day can earn 2.08 million, for today's workers, a daily salary of thousands is a luxury, not to mention a million a day, this is how many workers cannot earn a lifetime of the number[3].

\section{APPLICATION OF THE SLEEPER EFFECT IN ZHENG SHUANG'S SURROGACY INCIDENCE}

A sleeper effect is a psychological approach and theory that relate to persuasion and communication. It was first identified in U.S soldiers during world war 2 and is measured and evaluated by Hovland.

There are two expressions of the sleeper effect. According to this effect, when people are exposed to a 
highly persuasive message, their attitudes toward the advocacy of the message show a significant increase. However, over time, their attitude will slowly fall back to their previous attitude, and the impact of the message on them will shrink greatly. This is because the message receivers remember the highly persuasive sender at first. After some time, they gradually forget who the sender is and only remember the message. In another way, when people receive information related to a discounting cue, like a non-credible source, they will be more persuaded later in time comparing to just received the information [7]. This is because people will gradually forget who the sender is, and all they remember is the message itself. In addition, the increase in persuasion was stronger when recipients of discounting cues had a higher ability or motivation to think about the message and received the discounting cue after the message.

Often, it is assumed that the impact of a persuasive message on audiences' attitudes is strongest immediately after the communication and loses its impact over time. However, the sleeper effect denotes a delayed increase in persuasive following a communication accompanied by a discounting cue, which is "information indicating the untrustworthiness of the communication". These two phenomena are both present in Zhengshuang's case.

When the incident just happened, as Zheng Shuang's boyfriend, one of the closest contact acquaintances of Zhengshuang, provided a photo about himself and two children and posted it on Weibo. The information provided by Zhang heng was considered a high-reliability source. People were shocked by the information he shared, and the "indifference and selfishness" of Zhengshuang's family quickly ignite the public's emotion. The ethical conflicts and morality concerns made the public agrees quickly. In the next two days, the event swept all levels of society, with a high degree of public participation and discussion, forming a public social topic. Its development speed and influence far exceeded the event itself and became a social, moral, and ethical issue. At this point, the public, which is the receiver of the message, strongly believes in the credibility of Zhangheng's source.

Although Zhengshuang had posted relevant information to explain the situation and pointed out Zhangheng's mistakes. For example, Zhengshuang has posted Weibo stated, "This is a very sad and private matter for me" and said "did not violate the state's instructions while on Chinese soil and respected all laws and regulations while abroad"[8], the net citizens refused to accept and see her view because of the fact that Zhengshuang did choose to do surrogacy and had the will to abandon the children, which are forbidden and illegal to do in China[8].

With the wide and rapid spread of the Internet, the conflict between public psychology and specific event keeps expanding. While the public is criticizing
Zhengshuang's behavior and decision, multiple sources began to enroll in the trustworthiness of the incident. On January 19th, 2021, Zhengshuang's father post criticism toward Zhang heng on "cut off meaning to unscrupulously quote out of context". He also stated on Weibo, calling Zhangheng and his family "sinister and crafty scumbags", and saying Zhangheng has "indecent footage of other women on his phone"[9]. This can be seen as a discounting cue-that is, information that challenges the trustworthiness of the high-reliability source-- of Zhangheng's communication. At this point, the sleeper effect may evolve.

This post's effect was far less than the one Zhangheng posted because net citizens focus on Zhangheng's words. $\mathrm{He}$ seems to be a persuasive man because there is photographic evidence, birth certificates and audio recordings to support his views.

Only when people started to take on Zhengshuang's perspective, stand on a relatively just standpoint, they started to recognize that Zhangheng also has responsibility for agreeing to surrogacy. It is also true that Zhang did borrow 20 million yuan from Zheng Shuang and didn't repay Zhengshuang yet. The intention of Zhangheng is also questioned, why would he share his ex-girlfriend's personal matter to the public like that, let the internet torture her, and eventually crushed her career? All of these comments started to emerge and manifest, Zhengshuang and Zhangheng's events started to get more and more complicated.

The sleeper effect played an important role in Zhangheng and Zhengshuang's case. It can push the public voice to form. It can also de-escalate public voice. The high persuasive message can gradually lose its power as the low persuasive message gradually manifests, all of them due to people gradually forgetting about who the sender is.

\section{CONCLUSION}

From this article, the media, mainstream opinion, distance of events from the public, and reliability of the information sources can guide public opinion. And actually, it's the effect of the spiral of silence theory, the third effect, and the sleeper effect.

At the beginning of this incident, public opinion was influenced by the media and mainstream opinion. The public was more concerned about the topic of surrogacy, which the spiral of silence theory can explain. Through the third person, theory aroused the public's upsurge. It aroused the public's resonance in abandoning children and income to push the Zheng Shuang incident to a climax. And according to the sleeper effect, the information provided by Zhang heng was considered a high-reliability source. People were shocked by the information he shared. The "indifference and selfishness" of Zhengshuang's family quickly ignite the public's 
emotion, which led that the public turned the topic to ethical conflicts and morality concerns.

\section{REFERENCES}

[1] Elizabeth-Noel-Neumann. The Spiral of Silence: Public Opinion — Our Social Skin [M]. Peking University Press, 2013

[2] News and Communication: Review of "Silent Spiral" in the Era of New Media, [Online]Available:https://zhuanlan.zhihu.com/p/59 372800

[3] Annie Liu. Break the silence, how does the mainstream media guide the public opinion[J/OL]. https://www.hubpd.com/c/2018-0725/754851.shtml, 2018-07-25

[4] About the third party effect Baidu Baike [DB/OL]. https://baike.baidu.com/item/\%E7\%AC\%AC\%E4 \%B8\%89\%E4\%BA\%BA\%E6\%95\%88\%E6\%9E\% $9 \mathrm{C} / 576127$ ? $\mathrm{fr}=$ aladdin.

[5] Yang Linyu on the timeline of Zheng Shuang and Zhang Heng's Surrogacy Event [DB/OL] http://www.hxnews.com/news/yl/mxbg/202101/20/ 1956225.shtml. 2021.1.20

[6] Mother said that Zheng Shuang earned 2.08 million yuan a day, and I cried for the migrant workers [DB/OL]

https://new.qq.com/rain/a/20210428A0AO5000.

2021.4.28

[7] Kumkale, G. T., \& Albarracín, D. (2004, January). The sleeper effect in persuasion: a metaanalytic review. Psychological bulletin. https://www.ncbi.nlm.nih.gov/pmc/articles/PMC31 00161/.

[8] Gan, N. (2021, January 23). Accused of abandoning two babies in the US, Chinese celebrity sparks national debate about surrogacy. CNN. https://www.cnn.com/2021/01/22/china/chinacelebrity-surrogacy-scandal-dst-intl-hnk/index.html.

[9] Surrogacy Abandonment Scandal Captivates and Enrages Chinese Social Media. RADII. (2021, January 21). https://radiichina.com/zheng-shuangsurrogacy/. 